\title{
Heavy-Metal Contents and the Impact of Roasting on Polyphenols, Caffeine, and Acrylamide in Specialty Coffee Beans
}

\author{
Matúš Várady ${ }^{1, *}$, Sylwester Ślusarczyk ${ }^{2}$ (D) Jana Boržíkova ${ }^{3}$, Katarína Hanková ${ }^{4}$, Michaela Vieriková ${ }^{4}$, \\ Slavomír Marcinčák ${ }^{1}$ (D) and Peter Popelka ${ }^{1, *}$
}

check for

updates

Citation: Várady, M.; Ślusarczyk, S.; Boržíkova, J.; Hanková, K.; Vieriková,

M.; Marcinčák, S.; Popelka, P.

Heavy-Metal Contents and the

Impact of Roasting on Polyphenols,

Caffeine, and Acrylamide in Specialty Coffee Beans. Foods 2021, 10, 1310 https://doi.org/10.3390/foods10061310

Academic Editors: Cláudia P. Passos, Ana S. P. Moreira and Anna Vallverdú-Queralt

Received: 5 April 2021

Accepted: 3 June 2021

Published: 7 June 2021

Publisher's Note: MDPI stays neutral with regard to jurisdictional claims in published maps and institutional affiliations.

Copyright: (C) 2021 by the authors. Licensee MDPI, Basel, Switzerland. This article is an open access article distributed under the terms and conditions of the Creative Commons Attribution (CC BY) license (https:// creativecommons.org/licenses/by/ $4.0 /)$
1 Department of Food Hygiene, Technology and Safety, University of Veterinary Medicine and Pharmacy, Komenského 73, 04181 Košice, Slovakia; slavomir.marcincak@uvlf.sk

2 Department of Pharmaceutical Biology and Botany, Wroclaw Medical University, Borowska 211, 50-556 Wroclaw, Poland; sylwester.slusarczyk@umed.wroc.pl

3 State Veterinary and Food Institute Dolný Kubin, Hlinkova 619, 04365 Košice, Slovakia; borzikova@svu-ke.sk

4 State Veterinary and Food Institute Dolný Kubin, Jánošková 1611, 02601 Dolný Kubín, Slovakia; katarina.hankova@svpu.sk (K.H.); miska.vierikova@svpu.sk (M.V.)

* Correspondence: varadymatus@gmail.com (M.V.); peter.popelka@uvlf.sk (P.P.); Tel.: +42-19-0280-7549 (M.V.); +42-19-0511-0774 (P.P.)

Abstract: The aim of this study was to determine the effect of roasting on the contents of polyphenols $(\mathrm{PPH})$, acrylamide (AA), and caffeine (CAF) and to analyze heavy metals in specialty coffee beans from Colombia (COL) and Nicaragua (NIC). Samples of NIC were naturally processed and COL was fermented anaerobically. Green beans from COL (COL-GR) and NIC (NIC-GR) were roasted at two levels, light roasting (COL-LIGHT and NIC-LIGHT) and darker roasting (COL-DARK and NIC-DARK), at final temperatures of $210{ }^{\circ} \mathrm{C}(10 \mathrm{~min})$ and $215^{\circ} \mathrm{C}(12 \mathrm{~min})$, respectively. Quantitative analyses of PPH identified caffeoylquinic acids (CQA), feruloylquinic acids, and dicaffeoylquinic acids. Isomer 5-CQA was present at the highest levels and reached 60.8 and $57.7 \%$ in COL-GR and NIC-GR, 23.4 and 29.3\% in COL-LIGHT and NIC-LIGHT, and 18 and 24.2\% in COL-DARK and NIC-DARK, respectively, of the total PPH. The total PPH contents were highest in COL-GR (59.76 mg/g dry matter, DM). Roasting affected the contents of PPH, CAF, and AA $(p<0.001, p<0.011$ and $p<0.001$, respectively). Nickel and cadmium contents were significantly higher in the COL-GR than in the NIC-GR beans. Darker roasting decreased AA content, but light roasting maintained similar amounts of CAF and total PPH.

Keywords: specialty coffee; roasting; chlorogenic acids; caffeine; acrylamide; heavy metals; ultrahigh-resolution mass spectrometry; tandem mass spectroscopy

\section{Introduction}

The antioxidant activity of coffee beans depends on the characteristics of phenolic compounds, especially chlorogenic acids (CGA) and caffeine (CAF). Both CGA and CAF are important for flavor formation and the healthy effect of coffee brews and their extracts because they reduce oxidative stress and protect the antioxidant system [1,2]. CGA possesses a wide range of potential health benefits, which have been ascribed to the acyl-quinic acids in the brew and are associated with coffee consumption, including reduced incidences of several chronic and degenerative diseases such as cancer, cardiovascular disorders, diabetes, and Parkinson's disease [3]. Specialty coffee is the term for coffee that has a standardized process of production, from choosing criteria for coffee plantations to coffee brews that pass preliminary tests of grading and cupping. Only then can specialty coffees be served to the client $[4,5]$. One of the most important criteria is to achieve a cupping score of 80 points or above on the 100 point scale [4]. Farmers who process specialty coffee use the new types of coffee processing (anaerobic fermentation, carbonic macerations, thermal 
shock, etc.) to maintain the quality of coffee. Roasting is the most important operation responsible for the main chemical, physical, and organoleptic characteristics of the final coffee product [6]. When coffee is roasted at high temperatures, potentially toxic substances such as acrylamide (AA) are formed, mainly due to Maillard reactions between asparagine and reduced sugars such as glucose and fructose [6,7]. The development of AA depends on factors such as time and temperature, the degree of roasting, and the origin of the coffee $[8,9]$. AA develops early during roasting, reaching a maximum level within a few minutes, and then begins to decrease [10].

CAF is the most routinely ingested bioactive substance throughout the world. It is a natural methylxanthine alkaloid found in more than 60 plants, including coffee beans, tea leaves, cola nuts, and cocoa pods [11]. The quantity of CAF is greatly affected by the roasting level and decreases with the intensity of roasting [12,13].

Heavy metals are evaluated in coffees because they can be absorbed and stored by coffee plants in the roots, shoots, or grains, but the contents are usually much higher in the vegetative components than the grains [14]. Heavy metals are sources of contamination for humans because they accumulate in the food chain [15]. The bioavailability and occurrence of heavy metals, however, are influenced by other factors such as soil $\mathrm{pH}$, cation-exchange capacity, organic-matter content, soil texture, and interactions among elements [16].

The effect of roast degree on the contents of $\mathrm{AA}, \mathrm{CAF}$, and polyphenols (PPH) has already been studied extensively [17-19]. However, the influence of coffee type and roasting on the contents of total $\mathrm{PPH}, \mathrm{CAF}$, and AA has not yet been sufficiently studied in specialty coffees. We hypothesized that heavy-metal contents would vary substantially among green specialty coffee beans from different areas. Our goals were therefore to (1) identify the main bioactive compounds in specialty coffee beans (Colombian (COL) and Nicaraguan (NIC)); (2) determine the effects of coffee type and roasting on the contents of total PPH, CAF, and AA; and (3) determine the contents of heavy metals in green specialty coffee beans.

\section{Materials and Methods}

\subsection{Coffee Samples}

Samples of 100\% COL and NIC Coffea arabica beans (Project FOX Roastery, Prague, Czech Republic) were used in our experiment. The COL coffee was from the Finca La Cabana farm and was processed by anaerobic fermentation. The coffee seeds were fermented in plastic barrels sealed with one-way valves to prevent oxygen from entering but allowing oxygen to escape as the coffee ferments. Attaining an oxygen-free environment took about $25 \mathrm{~h}$. The coffees were fermented anaerobically for $200 \mathrm{~h}$ and then sun-dried. Parchment coffees were stored for 2-3 months to stabilize water activity and humidity. The NIC coffee was from the Finca Buena Vista farm and was processed using the natural method. It is a unique variety of Sarchimor, which is a coffee hybrid.

\subsection{Roasting}

The roasting of the green COL and NIC beans (COL-GR and NIC-GR, respectively) was done based on the degree of roasting. The light roasting (COL-LIGHT and NIC-LIGHT) was at a final temperature of $210{ }^{\circ} \mathrm{C}$ for $10 \mathrm{~min}$, and the development time was $30 \mathrm{~s}$. The darker roasting (COL-DARK and NIC-DARK, respectively) was at a final temperature of $215^{\circ} \mathrm{C}$ for $12 \mathrm{~min}$, and the development time was $2 \mathrm{~min}$ and $30 \mathrm{~s}$. The coffee was roasted in batch sizes of $0.25 \mathrm{~kg}$ in a Probatone 5 gas roaster (Probat, Emmerich am Rhein, Germany). The temperature was increased over time and depended on the amount of gas provided. The temperature was measured with a probe inside the drum of the roaster.

\subsection{Analysis of PPH}

Coffee samples were ground to fine powders using an FW 177 Herbal Medicine Disintegrator (Chincan, Tianjin, China) at 24, $000 \mathrm{rpm}$, and each $100 \mathrm{mg}$ was extracted three times with $80 \% \mathrm{MeOH}$ at $40{ }^{\circ} \mathrm{C}$ for $35 \mathrm{~min}$ in an ultrasonic bath. Particulate extracts were 
combined and evaporated to dryness and were then dissolved in $2 \mathrm{~mL}$ of Milli-Q water (acidified with $0.2 \%$ formic acid (FA)) and purified by solid-phase extraction (SPE) using a 60-mg Oasis HLB 3 cc Vac Cartridge (Waters Corp., Milford, CT, USA). The cartridges were washed with $0.5 \%$ methanol to remove carbohydrates and then washed with $80 \%$ methanol to elute the polyphenolic fraction. The polyphenolic fraction was re-evaporated to dryness and dissolved in $1 \mathrm{~mL}$ of $80 \%$ methanol (acidified with $0.2 \% \mathrm{FA}$ ). The sample was then centrifuged at 23, $000 \times g$ for 5 min and diluted five-fold with Milli-Q water before spectrometric analysis. All analyses were performed in triplicate for two independent samples and stored at $-20^{\circ} \mathrm{C}$ before analysis.

\subsection{Ultra-High-Resolution Mass Spectrometry (UHRMS)}

The particulate compounds from the $80 \% \mathrm{MeOH}$ SPE fraction containing PPH were analyzed using UHRMS on a Dionex UltiMate 3000RS system (Thermo Scientific, Darmstadt, Germany) with a charged aerosol detector connected to a compact QTOF mass spectrometer (Bruker Daltonik GmbH, Bremen, Germany). The coffee samples were chromatographically separated using a BEH C18 column $(2.1 \times 100 \mathrm{~mm}, 1.7 \mu \mathrm{M}$, Waters $)$ with mobile phase A consisting of $0.1 \%(v / v)$ FA in water and mobile phase B consisting of $0.1 \%$ FA $(v / v)$ in acetonitrile. The conditions of the initial mobile phase were $7 \% \mathrm{~B}$ and 93\% A held for $1 \mathrm{~min}$; then, from 1 to $20 \mathrm{~min}$, it was ramped concavely from $7 \%$ to $50 \%$ phase $\mathrm{B}$ in phase A to separate the phenolic compounds with a short $0.3 \mathrm{~min}$ calibration segment from 0 to $0.5 \mathrm{~min}$. The flow rate was $0.3 \mathrm{~mL} / \mathrm{min}$, and the column was held at $25^{\circ} \mathrm{C}$. Spectra were acquired in negative-ion mode over a mass range from $\mathrm{m} / \mathrm{z} 100$ to 1500 with a frequency of $5 \mathrm{~Hz}$. The operating parameters of the electrospray ion source were: capillary voltage, $3 \mathrm{kV}$; dry gas flow, $6 \mathrm{~L} / \mathrm{min}$; dry gas temperature, $200^{\circ} \mathrm{C}$; nebulizer pressure, 0.7 bar; collision radio frequency, $6000 \mathrm{~V}$; transfer time, $70.0 \mu \mathrm{s}$; and prepulse storage, $7.0 \mu \mathrm{s}$. Ultrapure nitrogen was used as the drying and nebulizer gas, and argon (Ar) was used as the collision gas. The collision energy was set automatically from 15 to $75 \mathrm{eV}$ depending on the $\mathrm{m} / \mathrm{z}$ of the fragmented ion. The data were calibrated internally with sodium formate introduced to the ion source at the beginning of each separation via a $20 \mu \mathrm{L}$ loop. Spectral data were acquired and processed using Bruker DataAnalysis 4.3 software. The concentrations of the phenolic compounds were calculated as equivalents of chlorogenic acid. Calibration curves were constructed based on five concentration points (from 0.23 to $0.000718 \mathrm{mg} / \mathrm{mL}$ ) using Bruker QuantAnalysis 4.3 software. All analyses were performed in triplicate.

\subsection{Analysis of CAF}

The samples of ground coffee were homogenized with the addition of Carez I $\left(\mathrm{K}_{4}[\mathrm{Fe}\right.$ $\left.\left.(\mathrm{CN})_{6}\right] 3 \mathrm{H}_{2} \mathrm{O}\right)$ and Carez II $\left(\mathrm{ZnSO}_{4} 7 \mathrm{H}_{2} \mathrm{O}\right)$ solutions and extracted at high temperature. HighPerformance Liquid Chromatography HPLC analyses were performed on an AGILENT 1200 chromatograph (Agilent Technologies, Santa Clara, CA, USA) equipped with a DAD detector $(212 \mathrm{~nm})$. The samples were chromatographically separated using an LC 18 column $(4 \times 125 \mathrm{~mm}, 5 \mu \mathrm{M})($ Merck KGaA, Darmstadt, Germany) with mobile phase A consisting of an acetate buffer and mobile phase B consisting of acetonitrile, with isocratic elution [20]. The CAF peak was detected at a wavelength of $212 \mathrm{~nm}$.

\subsection{Analysis of $A A$}

The samples of ground coffee were homogenized with the addition of the Carez I and Carez II solutions. The samples were extracted using acetonitrile and hexane, SPE, glass column packed with Hydromatrix, and evaporated on a rotary evaporator. The AA contents of the roasted samples were determined using a Dionex Ultimate 3000 chromatograph (Thermo Scientific, Waltham, MA, USA). The compounds were separated using a C18 Waters Acquity UPLC BEH chromatographic column $(2.1 \times 100 \mathrm{~mm}, 1.7 \mu \mathrm{M}$,). The mobile phase was acetonitrile and water (FA as an additive), with gradient elution. AA was detected using an ABSCIEX QTRAP 5500 system (Sciex, Framingham, MA, USA) [21,22]. 


\subsection{Analysis of Heavy Metals}

The coffee samples were ground to a standard grind and homogenized, weighed $(0.3 \mathrm{~g})$, and transferred to Merck Teflon beakers (Merck KGaA, Darmstadt, Germany) for mineralization. Five milliliters of $65 \%$ nitric acid and $1 \mathrm{~mL}$ of hydrogen peroxide were added. The Merck Teflon beakers were sealed and mineralized for $45 \mathrm{~min}$. The sample solutions were then quantitatively transferred to $25 \mathrm{~mL}$ volumetric flasks, and deionized water was added to bring the volume to $25 \mathrm{~mL}$ for analysis. The samples were digested in a Berghof MWS-2 microwave device (Berghof Automation GmbH, Eningen unter Achalm, Germany) for $45 \mathrm{~min}$ at temperatures ranging from 100 to $190{ }^{\circ} \mathrm{C}$. Heavy metals (copper, lead, chrome, cadmium (Cd), nickel (Ni), aluminum, and mercury) were identified using the multi-element technique of inductively coupled plasma mass spectrometry (Agilent ICP-MS 7900, Santa Clara, CA, USA). The ICP-MS conditions were: RF power, $1370 \mathrm{~W}$; RF matching, $1.58 \mathrm{~V}$; plasma gas (Ar) flow, $15 \mathrm{~L} / \mathrm{min}$; sampling depth, $7.9 \mathrm{~mm}$; carrier gas (Ar) flow, $1.22 \mathrm{~L} / \mathrm{min}$; nebulizer pump, $0.1 \mathrm{rps}$; and spray-chamber temperature, $2{ }^{\circ} \mathrm{C}$. The mercury was analyzed by atomic absorption spectrometry using an AMA-254 single-purpose atomic absorption spectrometer (Altec, Praha, Czech Republic).

\subsection{Statistical Analysis}

The data were analyzed using GraphPad Prism 8.3.0 (538) 2019 (GraphPad Software, Inc., San Diego, CA, USA). Data for total PPH, CAF, and AA were analyzed using two-way analyses of variance. The model included effects for coffee type, roast, and the coffee type $\times$ roast interaction. Individual differences were determined using Tukey's multiplecomparison post-test and were considered to be significant at $p<0.05$. Unpaired $t$-tests were applied to assess the differences in heavy-metal contents between the two types of green beans.

\section{Results}

\subsection{Bioactive Compounds of the Coffee Beans}

Quantitative analyses of the COL-GR, COL-LIGHT, and COL-DARK samples identified caffeoylquinic acids (CQA), feruloylquinic acids (FQA) and dicaffeoylquinic acids (diCQA), 5-caffeoylshikimic acid (5-CSKA), 3-caffeoylshikimic acid (3-CSKA) and 4caffeoylshikimic acid (4-CSKA), 5-O-p-coumaroylquinic acid ${ }^{1}$, and 3-O-p-coumaroylquinic acid glucoside ${ }^{2}$ (Table 1 ).

The chromatogram peak numbers in Figure 1 represent the main PPH of the COL-GR, COL-LIGHT, and COL-DARK samples as numbered in Table 1.

Quantitative analyses of the NIC-GR, NIC-LIGHT, and NIC-DARK samples identified caffeoylquinic acids (CQA), feruloylquinic acids (FQA) and dicaffeoylquinic acids (diCQA), 5-caffeoylshikimic acid (5-CSKA), 3-caffeoylshikimic acid (3-CSKA), and 4-caffeoylshikimic acid (4-CSKA) (Table 2).

The peak numbers in Figure 2 represent the main PPH of the Nicaraguan samples as numbered in Table 2. 
Table 1. Contents of main bioactive PPH (mg/g DM) in the Colombian coffee beans (COL-GR, COL-LIGHT, COL-DARK).

\begin{tabular}{|c|c|c|c|c|c|c|c|c|c|c|}
\hline No. & RT (min) & UV (nm) & $m / z[\mathrm{M}-\mathrm{H}]^{-}$ & MS $^{2}$ Main Ion & MS $^{2}$ Fragments & Formula & Compound & COL-GR & COL-LIGHT & COL-DARK \\
\hline 1 & 2.5 & 215,325 & 353.0874 & 191.0548 & $179,161,135$ & $\mathrm{C}_{16} \mathrm{H}_{18} \mathrm{O}_{9}$ & 3-O-CQA & $2.35 \pm 0.08$ & $5.05 \pm 0.74$ & \\
\hline 2 & 3.1 & 215,325 & 353.0871 & 191.0556 & $179,161,135$ & $\mathrm{C}_{16} \mathrm{H}_{18} \mathrm{O}_{9}$ & trans 3-O-CQA & & & $2.92 \pm 0.41$ \\
\hline 3 & 5.2 & 215,325 & 353.0881 & 191.0548 & $179,135,161$ & $\mathrm{C}_{16} \mathrm{H}_{18} \mathrm{O}_{9}$ & 5-O-CQA & $36.3 \pm 2.04$ & $14.0 \pm 1.02$ & \\
\hline 5 & 6.1 & 215,325 & 353.0877 & 191.0553 & & $\mathrm{C}_{16} \mathrm{H}_{18} \mathrm{O}_{9}$ & trans 5-O-CQA & & & $10.8 \pm 0.86$ \\
\hline 6 & 6.2 & 215,325 & 353.0877 & 191.0553 & 179,173 & $\mathrm{C}_{16} \mathrm{H}_{18} \mathrm{O}_{9}$ & 4-O-CQA & $3.93 \pm 0.06$ & $6.55 \pm 0.21$ & \\
\hline 7 & 6.8 & 215,325 & 367.1033 & 193.0493 & $134,149,173$ & $\mathrm{C}_{17} \mathrm{H}_{20} \mathrm{O}_{9}$ & trans 3-O-FQA & & & $0.51 \pm 0.02$ \\
\hline 8 & 7.1 & 215,325 & 353.0882 & 173.0439 & $179,191,134,155$ & $\mathrm{C}_{16} \mathrm{H}_{18} \mathrm{O}_{9}$ & trans 4-O-CQA & & & $5.05 \pm 0.08$ \\
\hline 10 & 7.8 & 215,325 & 337.0919 & 191.0545 & 173,163 & $\mathrm{C}_{16} \mathrm{H}_{18} \mathrm{O}_{8}$ & 5-O-p-CoQA ${ }^{1}$ & $0.43 \pm 0.01$ & & \\
\hline 11 & 8.8 & 215,325 & 335.0777 & 161.0228 & 135 & $\mathrm{C}_{16} \mathrm{H}_{16} \mathrm{O}_{9}$ & 5-CSKA & & $1.60 \pm 0.04$ & \\
\hline 12 & 8.9 & 215,325 & 367.1036 & 173.0438 & 193,134 & $\mathrm{C}_{17} \mathrm{H}_{20} \mathrm{O}_{9}$ & 5-O-FQA & $3.89 \pm 0.09$ & $0.72 \pm 0.02$ & \\
\hline 13 & 9.3 & 215,325 & 335.0778 & 161.0227 & 135 & $\mathrm{C}_{16} \mathrm{H}_{16} \mathrm{O}_{9}$ & trans 4-CSKA & & $1.35 \pm 0.07$ & \\
\hline 14 & 9.4 & 215,325 & 367.104 & 191.0548 & $173,155,134$ & $\mathrm{C}_{17} \mathrm{H}_{20} \mathrm{O}_{9}$ & trans 5-O-FQA & & & $1.53 \pm 0.02$ \\
\hline 15 & 9.5 & 215,325 & 367.1044 & 173.0439 & $191,156,134$ & $\mathrm{C}_{17} \mathrm{H}_{20} \mathrm{O}_{9}$ & trans 4-O-FQA & & & $0.72 \pm 0.02$ \\
\hline 16 & 9.8 & 215,325 & 335.0774 & 161.0224 & 179,135 & $\mathrm{C}_{16} \mathrm{H}_{16} \mathrm{O}_{8}$ & 3-CSKA & & & $0.45 \pm 0.01$ \\
\hline 17 & 9.9 & 215,325 & 335.0777 & 161.0228 & 135 & $\mathrm{C}_{16} \mathrm{H}_{16} \mathrm{O}_{9}$ & 5-CSKA & & & $1.86 \pm 0.07$ \\
\hline 18 & 10.4 & 215,325 & 335.0778 & 161.0227 & & $\mathrm{C}_{16} \mathrm{H}_{16} \mathrm{O}_{9}$ & 4-CSKA & & & $1.06 \pm 0.03$ \\
\hline 20 & 11.9 & 215,325 & 515.1195 & 191.0547 & 353,179 & $\mathrm{C}_{25} \mathrm{H}_{24} \mathrm{O}_{12}$ & 4,5-DiCQA & $1.69 \pm 0.02$ & $0.81 \pm 0.02$ & \\
\hline 21 & 12.1 & 215,325 & 515.1196 & 353.0869 & $173,179,191,161$ & $\mathrm{C}_{25} \mathrm{H}_{24} \mathrm{O}_{12}$ & trans 3,4-DiCQA & & & $0.95 \pm 0.01$ \\
\hline 22 & 12.4 & 215,325 & 515.1195 & 191.0547 & 353,179 & $\mathrm{C}_{25} \mathrm{H}_{24} \mathrm{O}_{12}$ & trans 4,5-DiCQA & & & $0.77 \pm 0.01$ \\
\hline 23 & 12.5 & 215,325 & 515.1204 & 353.0874 & $173,179,191$ & $\mathrm{C}_{25} \mathrm{H}_{24} \mathrm{O}_{13}$ & 3,5-DiCQA & $7.06 \pm 0.74$ & $1.45 \pm 0.02$ & \\
\hline 24 & 13 & 215,325 & 515.1197 & 353.0874 & $173,179,191$ & $\mathrm{C}_{25} \mathrm{H}_{24} \mathrm{O}_{13}$ & trans 3,5-DiCQA & (1008 & & $0.97 \pm 0.01$ \\
\hline 25 & 13 & 215 & 499.1246 & 337.0928 & 163 & $\mathrm{C}_{25} \mathrm{H}_{24} \mathrm{O}_{11}$ & 3-O-p-CoQA-Gluc ${ }^{2}$ & $2.47 \pm 0.04$ & & \\
\hline
\end{tabular}


Table 2. Contents of main bioactive PPH (mg/g DM) in the Nicaraguan coffee beans (NIC-GR, NIC-LIGHT, NIC-DARK).

\begin{tabular}{|c|c|c|c|c|c|c|c|c|c|c|}
\hline No. & RT (min) & UV (nm) & $m / z$ [M-H $^{-}$ & MS $^{2}$ Main Ion & MS $^{2}$ Fragments & Formula & Compound & NIC-GR & NIC-LIGHT & NIC-DARK \\
\hline 1 & 2.4 & 205,289 & 353.0874 & 191.0546 & $179,155,135$ & $\mathrm{C}_{16} \mathrm{H}_{18} \mathrm{O}_{9}$ & 3-O-CQA & $2.22 \pm 0.60$ & & \\
\hline 2 & 3.1 & 215,325 & 353.0871 & 191.0556 & $179,161,135$ & $\mathrm{C}_{16} \mathrm{H}_{18} \mathrm{O}_{9}$ & trans 3-O-CQA & & $4.40 \pm 0.21$ & $3.84 \pm 0.07$ \\
\hline 3 & 4.9 & 215,325 & 353.0872 & 191.0556 & & $\mathrm{C}_{16} \mathrm{H}_{18} \mathrm{O}_{9}$ & 5-O-CQA & $24.2 \pm 2.11$ & & \\
\hline 5 & 6.1 & 215,325 & 353.0877 & 191.0553 & & $\mathrm{C}_{16} \mathrm{H}_{18} \mathrm{O}_{9}$ & trans 5-O-CQA & & $12.3 \pm 1.22$ & $10.1 \pm 1.01$ \\
\hline 6 & 6.2 & 215,325 & 353.0884 & 173.044 & $179,191,135,155$ & $\mathrm{C}_{16} \mathrm{H}_{18} \mathrm{O}_{9}$ & 4-O-CQA & $2.97 \pm 0.08$ & & \\
\hline 7 & 6.8 & 215,325 & 367.1033 & 193.0493 & $134,149,173$ & $\mathrm{C}_{17} \mathrm{H}_{20} \mathrm{O}_{9}$ & trans 3-O-FQA & & $0.53 \pm 0.04$ & $0.40 \pm 0.02$ \\
\hline 8 & 7.1 & 215,325 & 353.0882 & 173.0439 & $179,191,134,155$ & $\mathrm{C}_{16} \mathrm{H}_{18} \mathrm{O}_{9}$ & trans 4-O-CQA & & $5.99 \pm 0.65$ & $4.67 \pm 0.08$ \\
\hline 11 & 8.8 & 215,325 & 367.1044 & 191.0552 & 173 & $\mathrm{C}_{17} \mathrm{H}_{20} \mathrm{O}_{9}$ & 5-O-FQA & $2.58 \pm 0.04$ & & \\
\hline 12 & 8.9 & 215,325 & 367.1041 & 191.0548 & $173,155,134$ & $\mathrm{C}_{17} \mathrm{H}_{20} \mathrm{O}_{9}$ & 3-O-FQA & $0.31 \pm 0.01$ & & \\
\hline 14 & 9.4 & 215,325 & 367.104 & 191.0548 & $173,155,134$ & $\mathrm{C}_{17} \mathrm{H}_{20} \mathrm{O}_{9}$ & trans 5-O-FQA & & $1.53 \pm 0.07$ & $1.41 \pm 0.06$ \\
\hline 15 & 9.5 & 215,325 & 367.1044 & 173.0439 & $191,156,134$ & $\mathrm{C}_{17} \mathrm{H}_{20} \mathrm{O}_{9}$ & trans 4-O-FQA & & $0.71 \pm 0.01$ & $0.58 \pm 0.02$ \\
\hline 16 & 9.8 & 215,325 & 335.0774 & 161.0224 & 179,135 & $\mathrm{C}_{16} \mathrm{H}_{16} \mathrm{O}_{8}$ & 3-CSKA & & $0.39 \pm 0.01$ & $0.48 \pm 0.01$ \\
\hline 17 & 9.9 & 215,325 & 335.0777 & 161.0228 & 135 & $\mathrm{C}_{16} \mathrm{H}_{16} \mathrm{O}_{9}$ & 5-CSKA & & $1.57 \pm 0.02$ & $1.89 \pm 0.04$ \\
\hline $17^{*}$ & 9.9 & 215,325 & 367.1038 & 179.033 & 161,135 & $\mathrm{C}_{17} \mathrm{H}_{20} \mathrm{O}_{9}$ & 4-O-FQA & $0.05 \pm 0.01$ & & \\
\hline 18 & 10.4 & 215,325 & 335.0778 & 161.0227 & & $\mathrm{C}_{16} \mathrm{H}_{16} \mathrm{O}_{9}$ & 4-CSKA & & $0.84 \pm 0.01$ & \\
\hline 19 & 11.7 & 215,325 & 515.1199 & 353.0869 & $173,179,191,161$ & $\mathrm{C}_{25} \mathrm{H}_{24} \mathrm{O}_{12}$ & 3,4-DiCQA & $3.52 \pm 0.06$ & & \\
\hline 20 & 11.9 & 215,325 & 515.1195 & 191.0547 & 353,179 & $\mathrm{C}_{25} \mathrm{H}_{24} \mathrm{O}_{12}$ & 4,5-DiCQA & $1.90 \pm 0.02$ & & \\
\hline 21 & 12.1 & 215,325 & 515.1196 & 353.0869 & $173,179,191,161$ & $\mathrm{C}_{25} \mathrm{H}_{24} \mathrm{O}_{12}$ & trans 3,4-DiCQA & & $1.05 \pm 0.01$ & $0.94 \pm 0.02$ \\
\hline 23 & 12.5 & 215,325 & 515.1204 & 353.0874 & $173,179,191$ & $\mathrm{C}_{25} \mathrm{H}_{24} \mathrm{O}_{13}$ & 3,5-DiCQA & $2.68 \pm 0.11$ & & \\
\hline 24 & 13 & 215,325 & 515.1197 & 353.0874 & $173,179,191$ & $\mathrm{C}_{25} \mathrm{H}_{24} \mathrm{O}_{13}$ & trans 3,5-DiCQA & & $1.00 \pm 0.01$ & $0.91 \pm 0.01$ \\
\hline
\end{tabular}

Values are means \pm SDs. SD- standard deviation, DM- dry matter, numbering in accordance with Table 1 , $^{*}$ additional peaks compared to the COL samples. 


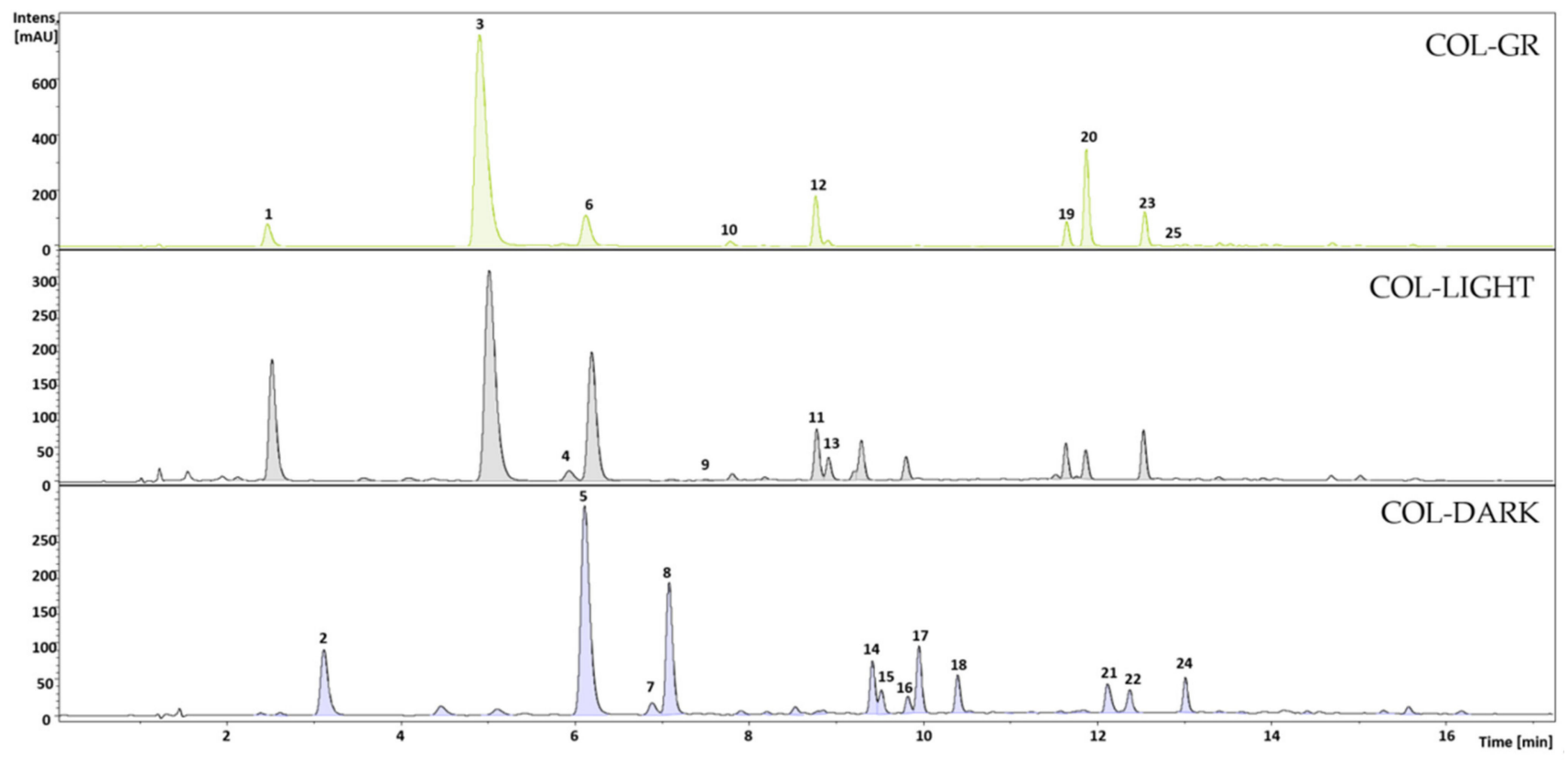

Figure 1. UV chromatograms at $320 \mathrm{~nm}$ for the $80 \% \mathrm{MeOH}$ extracts of the green (COL-GR), lightly roasted (COL-LIGHT), and darker roasted (COL-DARK) Colombian coffee samples. Peak numbers represent the main compounds of polyphenols listed (No.) in Table 1.

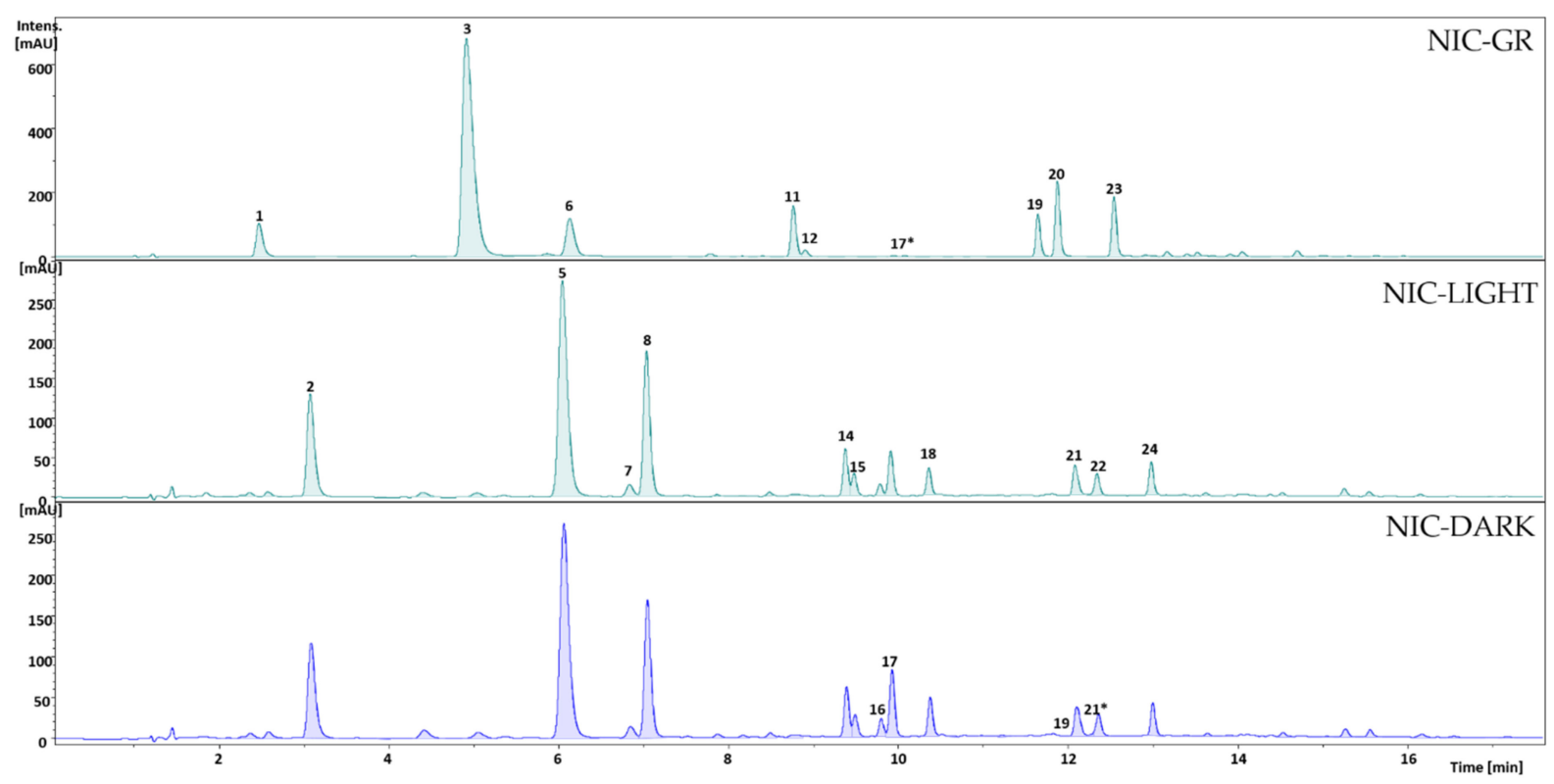

Figure 2. UV chromatograms at $320 \mathrm{~nm}$ of the $80 \% \mathrm{MeOH}$ extracts of the green (NIC-GR), lightly roasted (NIC-LIGHT), and darker roasted (NIC-DARK) Nicaraguan coffee samples. Peak numbers represent the main polyphenols listed (No.) in Table 2.

\subsection{Effect of Coffee Type and Roasting on CGA Content}

The effects of the type of coffee and roasting on CGA content are presented in Table 3. Roasting affected all CGA $(p<0.001)$. The strong similarity of NIC-LIGHT and NIC-DARK in UV chromatograms was observed. Coffee type significantly affected all contents, except for 3-O-CQA and 3-O-FQA. Coffee type and roasting interacted among the majority of CGA $(p<0.001)$. 
Table 3. Effects of coffee type and roasting on the contents of chlorogenic acids (mg/g DM).

\begin{tabular}{|c|c|c|c|c|c|c|c|c|c|c|}
\hline \multirow[t]{2}{*}{$\mathrm{C}$} & \multirow[t]{2}{*}{$\mathbf{R}$} & \multicolumn{3}{|c|}{ CQA (Cis and Trans) } & \multicolumn{3}{|c|}{ FQA (Cis and Trans) } & \multicolumn{3}{|c|}{ diCQA (Cis and Trans) } \\
\hline & & 3-O-CQA & 5-O-CQA & 4-O-CQA & 3-O-FQA & 5-O-FQA & 4-O-FQA & 3,4-diCQA & 4,5-diCQA & 3,5-diCQA \\
\hline \multirow{3}{*}{ COL } & GR & $2.35 \pm 0.08^{a}$ & $36.3 \pm 2.04^{b}$ & $3.93 \pm 0.06^{b}$ & $0.24 \pm 0.02^{a}$ & $3.89 \pm 0.09^{\mathrm{d}}$ & $0.0 \pm 0.00^{\mathrm{a}}$ & $0.05 \pm 0.01^{\mathrm{a}}$ & $1.69 \pm 0.02^{d}$ & $7.06 \pm 0.74^{d}$ \\
\hline & LIGHT & $5.05 \pm 0.74^{\mathrm{b}}$ & $14.0 \pm 1.02^{\mathrm{a}}$ & $6.55 \pm 0.21^{\mathrm{e}}$ & $0.55 \pm 0.02^{b}$ & $0.72 \pm 0.01^{\mathrm{a}}$ & $0.05 \pm 0.02^{b}$ & $0.96 \pm 0.07^{\mathrm{b}}$ & $0.81 \pm 0.02^{c}$ & $1.45 \pm 0.02^{b}$ \\
\hline & DARK & $2.92 \pm 0.41^{b}$ & $10.8 \pm 0.86^{\mathrm{a}}$ & $5.0 \pm 0.09^{c}$ & $0.51 \pm 0.02^{b}$ & $1.53 \pm 0.02^{b}$ & $0.72 \pm 0.02^{\mathrm{c}}$ & $0.95 \pm 0.01^{b}$ & $0.77 \pm 0.01^{\mathrm{c}}$ & $0.97 \pm 0.01^{\mathrm{a}}$ \\
\hline \multirow{3}{*}{ NIC } & GR & $2.22 \pm 0.60^{\mathrm{a}}$ & $24.2 \pm 2.11^{b}$ & $2.97 \pm 0.08^{a}$ & $0.31 \pm 0.01^{a}$ & $2.58 \pm 0.04^{c}$ & $0.05 \pm 0.01^{\mathrm{a}}$ & $3.52 \pm 0.06^{\mathrm{d}}$ & $1.90 \pm 0.02^{\mathrm{e}}$ & $2.68 \pm 0.11^{\mathrm{c}}$ \\
\hline & LIGHT & $4.40 \pm 0.21^{b}$ & $12.3 \pm 1.22^{\mathrm{a}}$ & $5.99 \pm 0.65^{\mathrm{d}}$ & $0.53 \pm 0.04^{b}$ & $1.53 \pm 0.07^{b}$ & $0.71 \pm 0.01^{\mathrm{c}}$ & $1.05 \pm 0.01^{\mathrm{c}}$ & $0.66 \pm 0.02^{b}$ & $1.00 \pm 0.01^{\mathrm{a}}$ \\
\hline & DARK & $3.84 \pm 0.07^{b}$ & $10.1 \pm 1.01^{\mathrm{a}}$ & $4.67 \pm 0.08^{c}$ & $0.40 \pm 0.02^{b}$ & $1.41 \pm 0.06^{\mathrm{a}}$ & $0.58 \pm 0.02^{\mathrm{d}}$ & $0.94 \pm 0.02^{b}$ & $0.66 \pm 0.01^{\mathrm{a}}$ & $0.91 \pm 0.01^{\mathrm{a}}$ \\
\hline $\mathrm{Co}$ & (C) & 0.148 & 0.001 & 0.001 & 0.492 & 0.001 & 0.001 & 0.001 & 0.001 & 0.001 \\
\hline & & 0.001 & 0.001 & 0.001 & 0.001 & 0.001 & 0.001 & 0.001 & 0.001 & 0.001 \\
\hline & & 0.001 & 0.001 & 0.053 & 0.068 & 0.001 & 0.001 & 0.001 & 0.001 & 0.001 \\
\hline
\end{tabular}

Values are means \pm SDs. SD, standard deviation. Different letters within a column indicate significant differences at $p<0.05$. 


\subsection{Effects of Coffee Type and Roasting on the Contents of Total PPH, CAF, and AA}

Coffee type and roasting affected the contents of total PPH $(p<0.001$, Table 4$)$. The content was highest in COL-GR. Roasting affected CAF content $(p<0.011)$, but the contents did not differ among the coffee types. AA content was affected by roasting $(p<0.001)$ and was lower in both COL-DARK and NIC-DARK than COL-LIGHT and NIC-LIGHT, respectively $(p<0.01)$.

Table 4. Effects of coffee type and roasting on the contents of total polyphenols, caffeine, and acrylamide.

\begin{tabular}{|c|c|c|c|c|}
\hline Coffee & Roasting & $\begin{array}{l}\text { Total Polyphenols } \\
\text { (mg/g DM) }\end{array}$ & Caffeine (mg/kg) & Acrylamide $(\mu \mathrm{g} / \mathrm{kg})$ \\
\hline \multirow{3}{*}{ Colombian } & Green & $59.8 \pm 8.94^{b}$ & $11,104 \pm 777$ & $\mathrm{Nd}$ \\
\hline & Light & $35.5 \pm 3.64^{\mathrm{a}}$ & $12,660 \pm 886$ & $457 \pm 82.3^{b}$ \\
\hline & Darker & $30.1 \pm 4.56^{\mathrm{a}}$ & $12,329 \pm 863$ & $192 \pm 34.6^{\mathrm{a}}$ \\
\hline \multirow{3}{*}{ Nicaraguan } & Green & $41.9 \pm 6.44^{\mathrm{a}}$ & $11,127 \pm 779$ & $\mathrm{Nd}$ \\
\hline & Light & $32.8 \pm 4.15^{\mathrm{a}}$ & $12,822 \pm 898$ & $413 \pm 74.3^{b}$ \\
\hline & Darker & $30.0 \pm 2.56^{\mathrm{a}}$ & $12,868 \pm 901$ & $277 \pm 49.9^{\mathrm{a}}$ \\
\hline \multicolumn{5}{|c|}{ Significance of effects } \\
\hline \multicolumn{2}{|c|}{ Coffee $(\mathrm{C})$} & 0.002 & 0.559 & 0.590 \\
\hline \multicolumn{2}{|c|}{ Roasting (R) } & 0.001 & 0.011 & 0.001 \\
\hline \multicolumn{2}{|c|}{$\mathrm{C} \times \mathrm{R}$} & 0.054 & 0.865 & 0.115 \\
\hline
\end{tabular}

Values are means \pm SDs. SD, standard deviation; Nd, not detected. Different letters within a column indicate significant differences at $p<0.05$.

\subsection{Heavy Metal Contents in the Green Coffee Beans}

The contents of heavy metals did not differ between COL-GR and NIC-GR, except for $\mathrm{Cd}$ and $\mathrm{Ni}$ (Table 5). $\mathrm{Cd}(p<0.001)$ and $\mathrm{Ni}(p<0.03)$ contents, which were significantly higher in COL-GR than NIC-GR.

Table 5. Contents of heavy metals ( $\mathrm{mg} / \mathrm{kg}$, means \pm SDs) in the green specialty coffee beans.

\begin{tabular}{cccc}
\hline Heavy Metal & Colombian & Nicaraguan & $p$ \\
\hline Mercury & $0.0007 \pm 0.00003$ & $0.0007 \pm 0.00001$ & 0.626 \\
Copper & $10.9 \pm 2.33$ & $14.1 \pm 3.16$ & 0.225 \\
Lead & $0.13 \pm 0.02$ & $0.10 \pm 0.04$ & 0.341 \\
Chrome & $0.06 \pm 0.01$ & $0.06 \pm 0.01$ & 0.124 \\
Cadmium & $0.15 \pm 0.02$ & $0.01 \pm 0.01$ & 0.001 \\
Nickel & $0.63 \pm 0.07$ & $0.48 \pm 0.03$ & 0.03 \\
Aluminum & $4.27 \pm 0.53$ & $3.28 \pm 0.34$ & 0.054 \\
\hline
\end{tabular}

\section{Discussion}

CGA content differed between the COL and NIC beans, perhaps because the PPH content of green coffee beans can vary among varieties, geographic location, and postharvest processes before roasting. Climate conditions might also increase the exposure and vulnerability of coffee to pests and diseases and thus affect PPH content [23]. Analysis of the bioactive compounds of the COL and NIC samples indicated the presence of phenolic acids in three main CGA groups: CQA, FQA, and diCQA. The CGA content in the green beans agreed with the published total CGA contents of 4-9.2\% for C. arabica and 7-14.4\% for Coffea robusta [24,25]. Isomer 5-O-CQA is generally the most abundant CGA that forms beneficial bioactive compounds in green and roasted beans. The contents of the 5-O-CQA and 4-O-CQA isomers in our study were highest in the green beans for both coffees, but the content of the 5-O-CQA isomer was much higher in COL-GR than NIC-GR. It is well known that during coffee roasting, major changes occur in coffee bean composition that influence the antioxidant capacity of melanoidins and CGA content in a coffee brew [26]. Roasting conditions decreased the contents of the 5-O-CQA isomer by $61-70 \%$ for the COL coffees and by $49-58 \%$ for the NIC coffees, consistent with the decrease in the content of this isomer 
in roasted C. robusta (47-72\%) [27]. The contents of the 3-O-CQA and 4-O-CQA isomers of the COL and NIC coffees increased approximately two-fold after light and darker roasting, also in agreement with other results [27]. However, UV chromatograms showed a similarity between NIC-LIGHT and NIC-DARK polyphenols. This can be probably ascribed to coffee processing. Fermented coffee beans are higher in PPH contents than unfermented coffee beans [28], which is also consonant with our results for green coffee samples. However, the total PPH contents of all Nicaraguan coffee samples, NIC-LIGHT and NIC-DARK, were not significantly different (Table 4). Therefore, we hypothesize that the natural processing of green coffee beans (i.e., Nicaraguan coffee) can probably lead to better protection of $\mathrm{PPH}$ during light and medium roasting (i.e., $170-220^{\circ} \mathrm{C}$ ) [12]. The 5-O-CQA isomer content, however, is the main marker of the quality of coffee beans and various other natural products [29]. Studies with different roasting conditions have reported correlations between the quality of coffee beverages and isomer 5-O-CQA content in commercial [30] and specialty coffees [5]. The contents of diCQA isomers were also high in both green beans, especially COL-GR, where the 3,5-diCQA isomer content was as high as $7.06 \mathrm{mg} / \mathrm{g}$ DM. The content of the 3,5-diCQA isomer in our green C. arabica beans was significantly higher than the other isomers of this group, but the contents of diCQA isomers differ little in green C. robusta beans [31]. Furthermore, CGA contents in green C. arabica beans differ between geographic locations in Kenya and Columbia [32,33].

Studies comparing total PPH contents in specialty coffees are limited. A recent study of a variety of Ethiopian specialty coffee beans roasted from 150 to $200{ }^{\circ} \mathrm{C}$ for $7-15 \mathrm{~min}$, however, reported total PPH contents of $3.75,1.85,1.80$, and $0.43 \%$ for green and light-, medium-, and dark-roasted beans, respectively [5]. Total PPH contents in our study were slightly higher in both coffees. The total PPH contents in the COL coffees were 5.98, 3.55, and $3.12 \%$ for the green and the light and darker roasted beans, respectively. The NIC coffees had slightly lower total PPH contents of 4.19, 3.28, and 2.99\% for the green and the light and darker roasted beans, respectively. The losses of total PPH during roasting were $40-50 \%$ and $22-29 \%$ for the COL and NIC coffees, respectively. The losses of total PPH were generally higher from the COL beans, with $11-45 \%$ losses at $190-216^{\circ} \mathrm{C}$, than from the roasted C. robusta beans, with total PPH losses of $<24 \%$ at $190{ }^{\circ} \mathrm{C}$ [27].

Differences in total PPH contents can also be influenced by the method of cultivation, the origin of the coffee, storage conditions, climate condition, pests, and diseases. PPH can be a natural defense mechanism of plants against pests and diseases, so organic coffee might have a higher content because of fewer pesticides used in farming [34]. Generally, organic crops have higher concentrations of antioxidants, lower concentrations of cadmium, and a lower incidence of pesticide residues across regions and production seasons [35]. Therefore, organic coffee beans also have a higher content of total PPH than do conventional beans [12]. The health benefits of PPH in commercially available coffees vary with processing conditions and degree of roasting [36], but the average loss of total PPH from green to dark-roasted coffee can be nearly 93\% [30]. Specialty coffees have a similar trend of lower total PPH contents after roasting, but the average losses were substantially lower in our experiment and another study [5]. The differences in the content of total PPH in specialty coffee beverages also depend on the method of preparation (e.g., Hario V60, espresso, and pour-over) [37].

CAF content was similar in both the COL and NIC coffees but increased with roasting time. Lightly roasted coffees contain more $\mathrm{CAF}$, which decreases with more intense roasting due to the release of CAF from the cell walls of the roasted beans and/or as the beans lose weight from the degradation of other organic substances [13,27]. Similarly, CAF content varies substantially depending on the origin of the coffee and the method of roasting and beverage preparation. CAF content in green C. arabica beans ranges from 0.8 to $1.4 \%$ [24] and can also vary substantially in roasted beans of different cultivars [38]. The CAF content in most $C$. arabica cultivars is $>0.8 \%$, consistent with the typical Ethiopian standard for roasted coffee [39]. In addition, the higher CGA contents and CAF, which were consistent with the higher values of total PPH and antioxidant capacity, were observed in the coffee 
silverskin of C. robusta as compared to C. arabica [40]. The CAF content in our study was $1.1 \%$ in the green beans and $1.2-1.3 \%$ in the light and darker-roasted beans. The CAF content in Ethiopian specialty coffees is $1.5-1.6 \%$ for green beans but decreases greatly during roasting [5]. These findings for specialty coffees are consistent with recent studies suggesting that the level of CAF decreases with longer roasting times and is highest in light- and medium-roasted commercial coffees [12,41].

AA contents were 192 and $277 \mu \mathrm{g} / \mathrm{kg}$ in the COL-DARK and NIC-DARK beans and 457 and $413 \mu \mathrm{g} / \mathrm{kg}$ in the COL-LIGHT and NIC-LIGHT beans, respectively. AA contents were generally lower than in street and industrially processed powdered coffees (346 \pm 19 to $701 \pm 38 \mu \mathrm{g} / \mathrm{kg}$ and $442 \pm 14$ to $906 \pm 7 \mu \mathrm{g} / \mathrm{kg}$, respectively) [42]. AA contents in roasted and instant coffee recommended by the European Commission, however, are 400 and $850 \mu \mathrm{g} / \mathrm{kg}$, respectively [43]. The AA contents of the lightly roasted COL and NIC beans were slightly higher than the EU standards, but the darker roasted beans (COL-DARK and NIC-DARK) had lower AA contents, probably due to the "development time" during roasting, when the AA content peaks after the first crack and then begins to decrease. Minimizing AA formation during the processing of coffees is highly desirable, so more aspects should be considered, such as roasting temperature, time of the roast, type of roaster, the velocity of the roasting air, humidity, and the degradation of $\mathrm{PPH}$. C. robusta beans roasted under optimal conditions (e.g., $203{ }^{\circ} \mathrm{C}$, dry air, low velocity of roasting air) have a relatively low AA content $(31.9-85.8 \mu \mathrm{g} / \mathrm{kg}$ ) and a moderate level of degradation of PPH [27]. Different types of roaster (e.g., drum, fluidized bed, or traditional) produce different levels of AA, but drum roasters produce the best results at a medium degree of roasting $\left(175^{\circ} \mathrm{C}\right)[5]$. However, the function of the type of coffee and origin of roasted specialty coffee varieties must be also taken into account when evaluating the cup quality [5].

In contrast to roasted coffee, limited studies have compared the contents of heavy metals in green beans, but their results are mostly consistent with our results [44-46]. The contents of some metals in green beans change after roasting depending on the degree of roasting, but the levels of heavy metals in coffee are within the recommended limits [47]. The Cd content in our COL coffees was higher $(0.148 \pm 0.0241 \mathrm{mg} / \mathrm{kg})$ than in the majority of studies [44-47]. Cd content is rarely determined in coffee beans compared to other heavy metals because their contents are relatively low. The average $\mathrm{Cd}$ content $(0.013 \pm 0.008 \mathrm{mg} / \mathrm{kg})$ in green C. arabica and C. robusta beans from different geographical regions [44] is similar to the content in the NIC-GR beans in our experiment. The reason for the strongly significant difference $(p<0.001)$ between the COL-GR and NIC-GR Cd contents remains unknown. Of the other heavy metals, only the Ni content differed significantly between the COL-GR and NIC-GR beans. The total contents of heavy metals, especially Cd, in nature are $>55$-fold higher in South America than North America, with the main sources of pollution from rock weathering, fertilizers, pesticides, mining, and manufacturing [48]. These sources may be responsible for the significant differences in the $\mathrm{Cd}$ and $\mathrm{Ni}$ contents in the green beans in our experiment. $\mathrm{Cd}$ is nevertheless a contaminant that can accumulate in the environment, with a good correlation between soil and plants [49], but Cd intake estimated from plant-based beverages is low [50]. Interestingly, some studies strongly support the use of spent coffee grounds as an effective and economical adsorbent for the removal of cadmium, lead, and probably of other metal species from both industrial and drinking water [51,52].

Farmers only use sensorial analyses to evaluate the quality of specialty coffee. We therefore compared the bioactive substances and dangers that arose during the processing of coffee in our experiment to those of the coffees previously described. These substances may or may not occur in specialty coffee, even if processed properly, e.g., lightly roasted. Specialty coffee is considered to have the highest quality on the market, but the customer, roaster, and farmer do not know if it also contains more bioactive compounds. Methods other than sensorial analyses should therefore be considered for identifying substances in 
specialty coffee and evaluating its quality. This study should contribute to the development of a more analytical definition of quality in the future.

\section{Conclusions}

Total polyphenol contents were higher in COL-GR than the NIC-GR, but the Cd and $\mathrm{Ni}$ contents were higher in the COL than the NIC coffees. The darker roasts of both types of coffees had lower AA contents and similar CAF and total PPH contents as the light roasts for both types of coffees. Our study demonstrates that specialty coffees and the method of their production can preserve the content of bioactive compounds but also minimize harmful contaminants, which can benefit the health of consumers. Drinking healthy and traceable high-quality specialty coffees should be a goals in the future.

Author Contributions: Conceptualization, M.V. (Matúš Várady) and P.P.; methodology, M.V. (Matúš Várady); software, S.Ś.; validation, S.Ś., J.B. and K.H.; formal analysis, M.V. (Michaela Vieriková); investigation, M.V. (Matúš Várady); resources, M.V. (Matúš Várady); data curation, P.P.; preparation of original draft, M.V. (Matúš Várady); review and editing, P.P.; supervision, P.P.; project administration, P.P. and S.M.; funding acquisition, S.M. All authors have read and agreed to the published version of the manuscript.

Funding: This research was funded by the Slovak Research and Development Agency, grant number APVV-18-0039.

Data Availability Statement: Data available upon reasonable request to the corresponding author.

Acknowledgments: The authors are grateful to Project FOX Roastery, Prague, Czech Republic for their donation of the coffee samples.

Conflicts of Interest: The authors declare no conflict of interest.

\section{References}

1. Dziki, D.; Gawlik-Dziki, U.; Pecio, Ł.; Rózyło, R.; Swieca, M.; Krzykowski, A.; Rudy, S. Ground green coffee beans as a functional food supplement-preliminary study. LWT Food Sci. Technol. 2015, 63, 691-699. [CrossRef]

2. Jeszka-Skowron, M.; Sentkowska, A.; Pyrzyńska, K.; De Peña, M.P. Chlorogenic acids, caffeine content and antioxidant properties of green coffee extracts: Influence of green coffee bean preparation. Eur. Food Res. Technol. 2016, 242, 1403-1409. [CrossRef]

3. Tajik, N.; Tajik, M.; Mack, I.; Enck, P. The potential effects of chlorogenic acid, the main phenolic components in coffee, on health: A comprehensive review of the literature. Eur. J. Nutr. 2017, 56, 2215-2244. [CrossRef] [PubMed]

4. Poltronieri, P.; Rossi, F. Challenges in specialty coffee processing and quality assurance. Challenges 2016, 7, 19. [CrossRef]

5. Bolka, M.; Emire, S. Effects of coffee roasting technologies on cup quality and bioactive compounds of specialty coffee beans. Food Sci. Nutr. 2020, 8, 6120-6130. [CrossRef]

6. Soares, C.M.D.; Alves, R.C.; Oliveira, M.B.P.P. Chapter 24-Factors affecting acrylamide levels in coffee beverages. In Coffee in Health and Disease Prevention; Preedy, V.R., Ed.; Academic Press: Waltham, MA, USA, 2015; pp. 217-224. [CrossRef]

7. Rannou, C.; Laroque, D.; Renault, E.; Prost, C.; Sérot, T. Mitigation strategies of acrylamide, furans, heterocyclic amines and browning during the Maillard reaction in foods. Food Res. Int. 2016, 90, 154-176. [CrossRef]

8. Cagliero, C.; Ho, T.D.; Zhang, C.; Bicchi, C.; Anderson, J.L. Determination of acrylamide in brewed coffee and coffee powder using polymeric ionic liquid-based sorbent coatings in solid-phase microextraction coupled to gas chromatography-mass spectrometry. J. Chromatogr. A. 2016, 1449, 2-7. [CrossRef]

9. Alves, R.C.; Soares, C.; Casal, S.; Fernandes, J.O.; Oliveira, M.B.P.P. Acrylamide in espresso coffee: Influence of species, roast degree and brew length. Food Chem. 2010, 119, 929-934. [CrossRef]

10. Bertuzzi, T.; Martinelli, E.; Mulazzi, A.; Rastelli, S. Acrylamide determination during an industrial roasting process of coffee and the influence of asparagine and low molecular weight sugars. Food Chem. 2020, 303, 125372. [CrossRef]

11. De Mejia, E.G.; Ramirez-Mares, M.V. Impact of caffeine and coffee on our health. Trends Endocrinol. Metab. 2014, 25, 489-492. [CrossRef]

12. Król, K.; Gantner, M.; Tatarak, A.; Hallmann, E. The content of polyphenols in coffee beans as roasting, origin and storage effect. Eur. Food Res. Technol. 2020, 246, 33-39. [CrossRef]

13. Hecimovic, I.; Belscak-Cvitanovic, A.; Horzic, D.; Komes, D. Comparative study of polyphenols and caffeine in different coffee varieties affected by the degree of roasting. Food Chem. 2011, 129, 991-1000. [CrossRef]

14. Singh, S.; Zacharias, M.; Kalpana, S.; Mishra, S. Heavy metals accumulation and distribution pattern in different vegetable crops. J. Environ. Chem. Ecotoxicol. 2012, 4, 75-81. [CrossRef]

15. Da Silva, S.A.; Mendes, F.Q.; Reis, M.R.; Passos, F.R.; de Carvalho, A.M.X.; de Oliveira Rocha, K.R.; Pinto, F.G. Determination of heavy metals in the roasted and ground coffee beans and brew. Afr. J. Agric. Res. 2017, 12, 221-228. [CrossRef] 
16. Jung, M.C. Heavy metal concentrations in soils and factors affecting metal uptake by plants in the vicinity of a Korean Cu-W Mine. Sensors 2008, 8, 2413-2423. [CrossRef] [PubMed]

17. Vignoli, J.A.; Bassoli, D.G.; Benassi, M.T. Antioxidant activity, polyphenols, caffeine and melanoidins in soluble coffee: The influence of processing conditions and raw material. Food Chem. 2011, 124, 863-868. [CrossRef]

18. Vignoli, J.A.; Viegas, M.C.; Bassoli, D.G.; Benassi, M.T. Roasting process affects differently the bioactive compounds and the antioxidant activity of Arabica and Robusta coffees. Food Res. Int. 2014, 61, 279-285. [CrossRef]

19. Dybkowska, E.; Sadowska, A.; Rakowska, R.; Dębowska, M.; Świderski, F.; Świąder, K. Assessing polyphenols content and antioxidant activity in coffee beans according to origin and the degree of roasting. Rocz. Państw. Zakł. Hig. 2017, 68, 347-353.

20. Wanyika, H.N.; Gatebe, E.G.; Gitu, L.M.; Ngumba, E.K.; Maritim, C.W. Determination of caffeine content of tea and instant coffee brands found in the Kenyan market. Afr. J. Food Sci. 2010, 4, 353-358.

21. Wenzl, T.; Beatriz de la Calle, M.; Anklam, E. Analytical methods for the determination of acrylamide in food products: A review. Food Addit. Contam. 2003, 20, 885-902. [CrossRef]

22. Ono, H.; Chuda, Y.; Ohnishi-Kameyama, M.; Yada, H.; Ishizaka, M.; Kobayashi, H.; Yoshida, M. Analysis of acrylamide by LC-MS/MS and GC-MS in processed Japanese foods. Food Addit. Contam. 2003, 20, 215-220. [CrossRef]

23. Pham, Y.; Reardon-Smith, K.; Mushtaq, S.; Cockfield, G. The impact of climate change and variability on coffee production: A systematic review. Clim. Chang. 2019, 156, 609-630. [CrossRef]

24. Farah, A.; Donangelo, C.M. Phenolic compounds in coffee. Braz. J. Plant Physiol. 2006, 18, 23-36. [CrossRef]

25. Mussatto, S.I.; Machado, E.M.S.; Martins, S.; Teixeira, J.A. Production, composition, and application of coffee and its industrial residues. Food Bioprocess Technol. 2011, 4, 661-672. [CrossRef]

26. Smrke, S.; Opitz, S.E.; Vovk, I.; Yeretzian, C. How does roasting affect the antioxidants of a coffee brew? Exploring the antioxidant capacity of coffee via on-line antioxidant assays coupled with size exclusion chromatography. Food Funct. 2013, 4, 1082-1092. [CrossRef]

27. Budryn, G.; Nebesny, E.; Oracz, J. Correlation between the stability of chlorogenic acids, antioxidant activity and acrylamide content in coffee beans roasted in different conditions. Int. J. Food Prop. 2015, 18, 290-302. [CrossRef]

28. Haile, M.; Kang, W.H. Antioxidant Activity, Total Polyphenol, Flavonoid and Tannin Contents of Fermented Green Coffee Beans with Selected Yeasts. Fermentation 2019, 5, 29. [CrossRef]

29. Wianowska, D.; Gil, M. Recent advances in extraction and analysis procedures of natural chlorogenic acids. Phytochem. Rev. 2019, 18, 273-302. [CrossRef]

30. Farah, A.; Monteiro, M.C.; Calado, V.; Franca, A.S.; Trugo, L.C. Correlation between cup quality and chemical attributes of Brazilian coffee. Food Chem. 2006, 98, 373-380. [CrossRef]

31. Trugo, L.C.; Macrae, R. A study of the effect of roasting on the chlorogenic acid composition of coffee using HPLC. Food Chem. 1984, 15, 219-227. [CrossRef]

32. Bertrand, B.; Villarreal, D.; Laffargue, A.; Posada, H.; Lashermes, P.; Dussert, S. Comparison of the effectiveness of fatty acids, chlorogenic acids, and elements for the chemometric discrimination of coffee (Coffea arabica L.) varieties and growing origins. J. Agric. Food Chem. 2008, 56, 2273-2280. [CrossRef]

33. Gichimu, B.M.; Gichuru, E.K.; Mamati, G.E.; Nyende, A.B. Biochemical composition within Coffea arabica cv. Ruiru 11 and its relationship with cup quality. J. Food Res. 2014, 3, 31-44. [CrossRef]

34. Veberic, R. The Impact of Production Technology on Plant Phenolics. Horticulturae 2016, 2, 8. [CrossRef]

35. Barański, M.; Srednicka-Tober, D.; Volakakis, N.; Seal, C.; Sanderson, R.; Stewart, G.B.; Benbrook, C.; Biavati, B.; Markellou, E.; Giotis, C.; et al. Higher antioxidant and lower cadmium concentrations and lower incidence of pesticide residues in organically grown crops: A systematic literature review and meta-analyses. Br. J. Nutr. 2014, 112, 794-811. [CrossRef]

36. Mills, C.E.; Oruna-Concha, M.J.; Mottram, D.S.; Gibson, G.R.; Spencer, J.P.E. The effect of processing on chlorogenic acid content of commercially available coffee. Food Chem. 2013, 141, 3335-3340. [CrossRef]

37. Várady, M.; Hrušková, T.; Popelka, P. Effect of preparation method and roasting temperature on total polyphenol content in coffee beverages. Czech J. Food Sci. 2020, 38, 417-421. [CrossRef]

38. Kitzberger, C.; Scholz, M.; Benassi, M. Bioactive compounds content in roasted coffee from traditional and modern Coffea arabica cultivars grown under the same edapho-climatic conditions. Food Res. Int. 2014, 61-66. [CrossRef]

39. Silvarolla, B.; Mazzafera, P.; Alves de Lima, M.M. Caffeine content of Ethiopian Coffea arabica beans. Genet. Mol. Biol. 2000, 23, 213-215. [CrossRef]

40. Panusa, A.; Petrucci, R.; Lavecchia, R.; Zuorro, A. UHPLC-PDA-ESI-TOF/MS metabolic profiling and antioxidant capacity of arabica and robusta coffee silverskin: Antioxidants vs phytotoxins. Food Res Int. 2017, 99, 155-165. [CrossRef]

41. Górecki, M.; Hallmann, E. The antioxidant content of coffee and its in vitro activity as an effect of its production method and roasting and brewing time. Antioxidants 2020, 9, 308. [CrossRef]

42. Endeshaw, H.; Belay, A. Optimization of the roasting conditions to lower acrylamide content and improve the nutrient composition and antioxidant properties of Coffea arabica. PLoS ONE 2020, 15, e0237265. [CrossRef] [PubMed]

43. Commission Regulation (EU); Publications Office of the EU. Establishing Mitigation Measures and Benchmark Levels for the Reduction of the Presence of Acrylamide in Food. 2017/2158 of 20 November 2017. Available online: https:/ / op.europa.eu/en/ publication-detail/- / publication/1f3b45fb-ce6b-11e7-a5d5-01aa75ed71a1/language-en (accessed on 21 November 2017). 
44. Jeszka-Skowron, M.; Stanisz, E.; De Peña, M.P. Relationship between antioxidant capacity, chlorogenic acids and elemental composition of green coffee. LWT 2016, 73, 243-250. [CrossRef]

45. Şemen, S.; Mercan, S.; Yayla, M.; Açıkkol, M. Elemental composition of green coffee and its contribution to dietary intake. Food Chem. 2017, 215, 92-100. [CrossRef] [PubMed]

46. Endaye, M.; Atlabachew, M.; Mehari, B.; Alemayehu, M.; Mengistu, D.A.; Kerisew, B. Combining multi-element analysis with statistical modeling for tracing the origin of green coffee beans from Amhara region, Ethiopia. Biol. Trace Elem. Res. 2020, 195, 669-678. [CrossRef]

47. Adler, G.; Nędzarek, A.; Tórz, A. Concentrations of selected metals (Na, K, Ca, Mg, Fe, Cu, Zn, Al, Ni, Pb, Cd) in coffee. Zdr. Varst. 2019, 58, 187-193. [CrossRef]

48. Zhou, Q.; Yang, N.; Li, Y.; Ren, B.; Ding, X.; Bian, H.; Yao, X. Total concentrations and sources of heavy metal pollution in global river and lake water bodies from 1972 to 2017. Glob. Ecol. Conserv. 2020, 22, e00925. [CrossRef]

49. Genchi, G.; Sinicropi, M.S.; Lauria, G.; Carocci, A.; Catalano, A. The effects of cadmium toxicity. Int. J. Environ. Res. Public Health 2020, 17, 3782. [CrossRef]

50. Magri, E.; Valduga, A.T.; Gonçalves, I.L.; Barbosa, J.Z.; de Oliveira Rabel, D.; Menezes, I.M.N.R.; de Andrade Nascimento, P.; Oliveira, A.; Corrêa, R.S.; Motta, A.C.V. Cadmium and lead concentrations in yerba mate leaves from agroforestry and plantation systems: An international survey in South America. J. Food Compost. Anal. 2021, 96, 103702. [CrossRef]

51. Lavecchia, R.; Medici, F.; Patterer, S.; Zuorro, A. Lead removal from water by adsorption on spent coffee grounds. Chem. Eng. Trans. 2016, 47, 295-300. [CrossRef]

52. Patterer, S.; Bavasso, I.; Sambeth, J.; Medici, F. Cadmium removal from aqueous solution by adsorption on spent coffee grounds. Chem. Eng. Trans. 2017, 60, 157-162. [CrossRef] 